\title{
Influence of sowing date and irrigation on the growth and yield of pinto beans (Phaseolus vulgaris) in a sub- humid temperate environment
}

\author{
H. K. DAPAAH*, B. A. MCKENZIE AND G. D. HILL \\ Department of Plant Science, P.O. Box 84, Lincoln University, Canterbury, New Zealand
}

(Revised MS received 27 July 1999)

\begin{abstract}
SUMMARY
The growth and yield of pinto beans (Phaseolus vulgaris L.) cv. Othello in response to a total of six sowing dates (from October to December) and irrigation was examined over two seasons in Canterbury, New Zealand. In 1994/95, two irrigation treatments (nil and full) were combined with two sowing dates (27 October and 24 November). In 1995/96, Othello was examined under two irrigation treatments (nil and full) and four sowing dates (1 November, 15 November, 29 November and 13 December). The total rainfall for the two seasons was $50 \%$ and $60 \%$ of the long-term average, respectively. The mean temperatures for the seasons were similar to the long-term average. Both irrigation and sowing date had a marked effect on growth and seed yield. Averaged over both seasons, seed yield for fully irrigated crops was $337 \mathrm{~g} / \mathrm{m}^{2}, c .50 \%$ higher than the yield of unirrigated crops. The irrigated crops yielded more than the unirrigated crops because they attained greater canopy closure, intercepting $84-95 \%$ of incident radiation. They also had on the average $47 \%$ higher leaf area duration (LAD), $72 \%$ higher maximum leaf area index (LAI) and greater utilization coefficient. The mid- to late November-sown crops yielded more than the late October to early November and December-sown crops because the leaf area of the former increased most rapidly, achieved a higher maximum LAI and LAD and consequently intercepted more photosynthetically active radiation (PAR). They also had faster pod growth rates and $26 \%$ of stored assimilates contributed to pod growth compared with $13 \%$ in late October to early November and $5 \%$ in December-sown crops. The results showed that pinto beans can grow and yield well in Canterbury, and that a yield advantage could be obtained when sown in mid- to late November and with irrigation.
\end{abstract}

\section{INTRODUCTION}

In New Zealand, pinto beans (Phaseolus vulgaris L.) are a potentially new, alternative legume to peas (Pisum sativum L.) which are grown as a rotational crop with cereals and grass seed. Because of huge export opportunities to the USA, Canada and Latin America, pinto beans can be a new, profitable crop for farmers in New Zealand and thereby reduce the economic risk of depending on traditional crops.

To determine the yield potential of pinto beans will require an understanding of the processes that contribute to the development, growth and yield of the crop and the effect of the environment on these processes. Seed yield is the ultimate consequence of the amount of dry matter (DM) accumulated during

\footnotetext{
* To whom all correspondence should be addressed at: Crops Research Institute, P.O. Box 3785, Kumasi, Ghana. Email: criggdp@ghana.com
}

the growing season and the partitioning of the DM into seeds.

The time of sowing a crop is a critical factor in determining the environmental conditions at planting, anthesis, pod-filling and drying. Therefore, sowing date can be important in determining the success of the crop and in maximizing seed yield. Hence, there is the need to determine the optimum sowing time for the introduced pinto beans in Canterbury's shortseason environment often characterized by early spring frosts, low night temperatures and dry conditions.

Most crops in Canterbury require irrigation to achieve maximum yields (McKenzie \& Hill 1990). Irrigation has been found to more than double the yield of peas (Pisum sativum L.; White et al. 1982) and field beans (Vicia faba L.; Husain et al. 1983) in Canterbury. However, lentils (Lens culinaris Medik.) responded little to irrigation in Canterbury (McKenzie et al. 1985). 
Field experiments were conducted during the 1994/95 and 1995/96 seasons at Lincoln University, Canterbury, New Zealand to examine the influence of sowing date and irrigation on the growth and yield of pinto beans.

\section{MATERIALS AND METHODS}

The experiments were conducted at the Lincoln University Iversen research area on a Wakanui silt loam (Anon. 1968). The sites had been in potatoes (Solanum tuberosum) and barley (Hordeum vulgare L.) in the previous season, before the 1994/95 and $1995 / 96$ experiments, respectively. Soil fertility was moderately high in both seasons according to the New Zealand Ministry of Agriculture and Fisheries soil test.

The first experiment (1994/95) was a split-plot randomized complete block design with two irrigation treatments (nil and full) as main plots. Subplots consisted of a factorial combination of two sowing dates (27 October and 24 November) and three inoculation treatments (nil, Rhizobium phaseoli strains CC511 and RCR3644). Grain legumes are generally not inoculated in New Zealand but it was not known whether this applied to pinto beans. The six subplot treatments were assigned randomly within each main plot. There were four replicates. Each subplot measured $8 \mathrm{~m}$ long with 10 rows each $15 \mathrm{~cm}$ apart.

The second experiment (1995/96) was also a splitplot design. The treatments again consisted of two irrigation levels (nil and full) as main plots but there were four sowing dates (1 November, 15 November, 29 November and 13 December) as subplots. Each subplot was $10 \mathrm{~m}$ long with 14 rows each $15 \mathrm{~cm}$ apart. There were four replicates.

Irrigation was applied according to calculated soil moisture deficit (SMD). In both seasons, fully irrigated plots received $16 \mathrm{~mm}$ of water whenever the calculated SMD reached $25 \mathrm{~mm}$. There were three applications in 1994/95 and six applications in $1995 / 96$. However, in $1994 / 95$, there were two occasions when irrigation equipment was not available when irrigation was needed but could not be applied.

In both years before sowing, the sites were cultivated by ploughing, dutch harrowing and rolling to produce the seed bed. Trifluralin was applied pre-emergence at $800 \mathrm{~g}$ a.i./ ha to control weeds. Herbage growth in the fallow plots for the later sowing dates and from sown plots was controlled by hoeing. All plots were sown using pinto bean cv. Othello with an Øyjord cone seeder to give a plant population of $c .60$ plants $/ \mathrm{m}^{2}$ in both seasons. In 1994/95, seed was treated with captan 400 (a.i. captan $800 \mathrm{~g} / \mathrm{kg}$ ) at a rate of $140 \mathrm{~g}$ per $100 \mathrm{~kg}$ of seed. The Rhizobium strains were applied at $240 \mathrm{~g}$ of inoculum per $100 \mathrm{~kg}$ of bean seed in a slurry form. The inoculated seeds were allowed to dry and sown $2-3 \mathrm{~h}$ after inoculation. In the second year, seeds were inoculated with only CC511 rhizobium (at the same rate as above) and treated with the fungicide Apron 70SD (a.i. metalaxyl $350 \mathrm{~g} / \mathrm{kg}$ and captan $350 \mathrm{~g} / \mathrm{kg}$ ) at the rate of $100 \mathrm{~g}$ (dissolved in $250 \mathrm{ml}$ of water) per $50 \mathrm{~kg}$ of seed.

\section{Measurements}

In both years the final plant population, seed and dry matter yields and harvest index (HI) were estimated from a $2 \cdot 0 \mathrm{~m}^{2}$ harvest area from the central four rows of each sub-plot at harvest maturity. Dry matter accumulation was measured using $0.2 \mathrm{~m}^{2}$ samples randomly cut from each subplot. In the first year, sampling was done on each plot every 2 weeks from 28 days after sowing (DAS), while in the second season, it was done every 10 days from 28 DAS. To determine the partitioning of DM after flowering, plant components such as leaves, stems and pods were separated from the $0.2 \mathrm{~m}^{2}$ samples, oven dried $\left(70{ }^{\circ} \mathrm{C} \pm 2{ }^{\circ} \mathrm{C}\right)$ and weighed.

Generalized logistic curves (Gallagher \& Robson 1984) were used to describe dry-matter accumulation of the crop. The functional growth analysis was made using the Maximum Likelihood Programme (MLP) from Rothamsted (Ross et al. 1987).

Leaf area index (LAI) and the amount of radiation transmitted through the canopy $\left(T_{i}\right)$ were measured in both experiments using a LICOR LAI 2000 Plant Canopy Analyser (LI-COR, Lincoln, Nebraska). Leaf area duration (LAD) was calculated as the time integral of leaf area index (Hunt 1978). To examine the importance of photosynthetic area during the reproductive phase, post-flowering LAD was estimated (i.e. time integral of LAI after flowering to physiological maturity). In 1994/95, LAI and $T_{i}$ were measured every 2 weeks from 28 DAS until physiological maturity. In 1995/96, LAI and $T_{i}$ were measured every 10 days from 28 DAS. The proportion of radiation intercepted $\left(F_{i}\right)$ by the canopy and the amount of photosynthetically active radiation (PAR) intercepted were calculated according to Gallagher \& Biscoe (1978) and Szeicz (1974).

All statistical analyses were done using the Statistical Analysis Systems Institute (SAS) package (Anon. 1988).

\section{RESULTS}

\section{Climate}

All climatic data were recorded at the Broadfield Meteorological Station, Lincoln University, sited $1.0 \mathrm{~km}$ from the experimental site. In 1994/95, the mean maximum and minimum temperatures were similar to the long-term averages. Total rainfall from October 1994 to March 1995 was $154 \mathrm{~mm}$, c. $50 \%$ of the long-term average, making the season drier than usual. Solar radiation from November 1994 to 

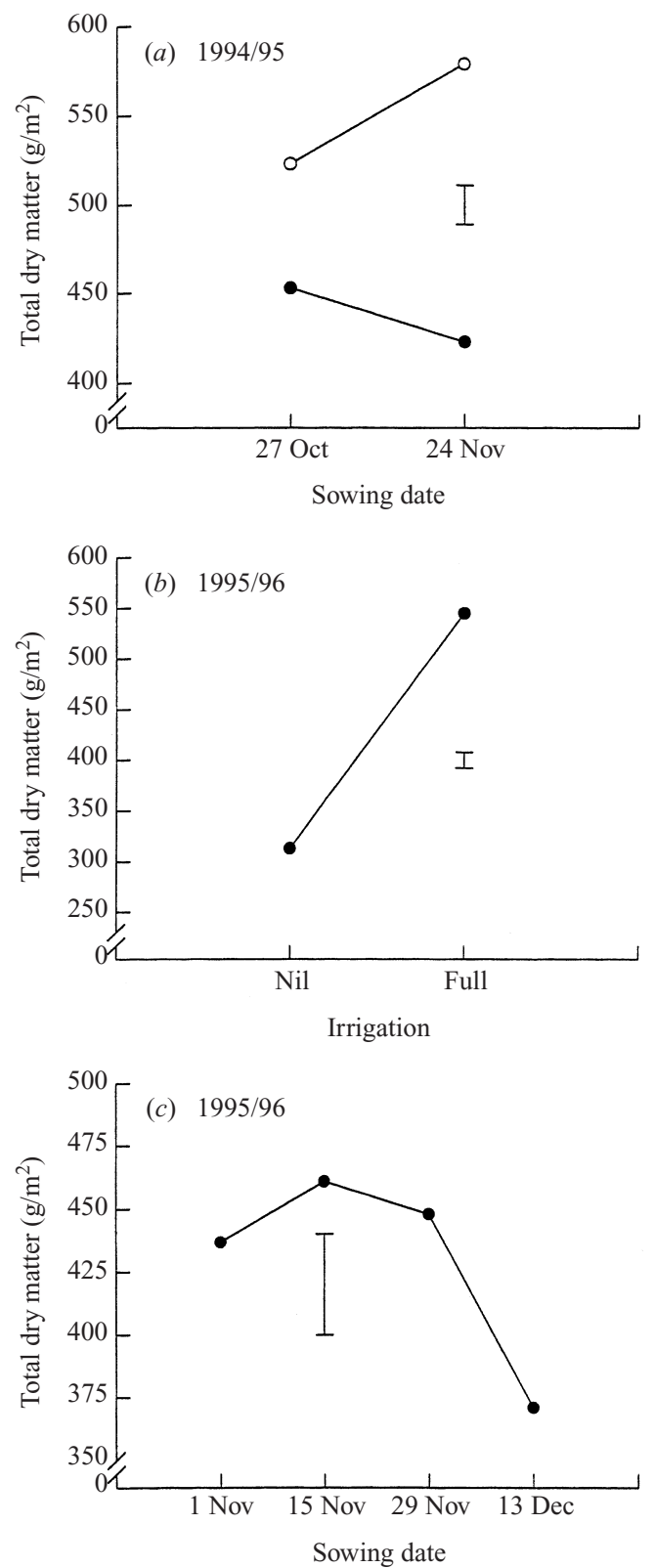

Fig. 1. (a) The irrigation $\times$ sowing date interaction on pinto beans total dry matter at harvest in 1994/95; (unirrigated $(\bullet)$, irrigated $(O)$; $\mathrm{I}=$ S.E.M, error D.F. $=30$ ); and the effects of $(b)$ irrigation and $(c)$ sowing date on total dry matter at harvest in 1995/96 (error for $(b)=3$ and $(c)=18$ ).

January 1995 was $c .19 \%$ higher than the long-term average. Penman evapo-transpiration (EPT) was $c$. $11 \%$ higher than normal for November-December 1994. The 1995/96 season was also drier than the long-term average, with total rainfall receipt (188
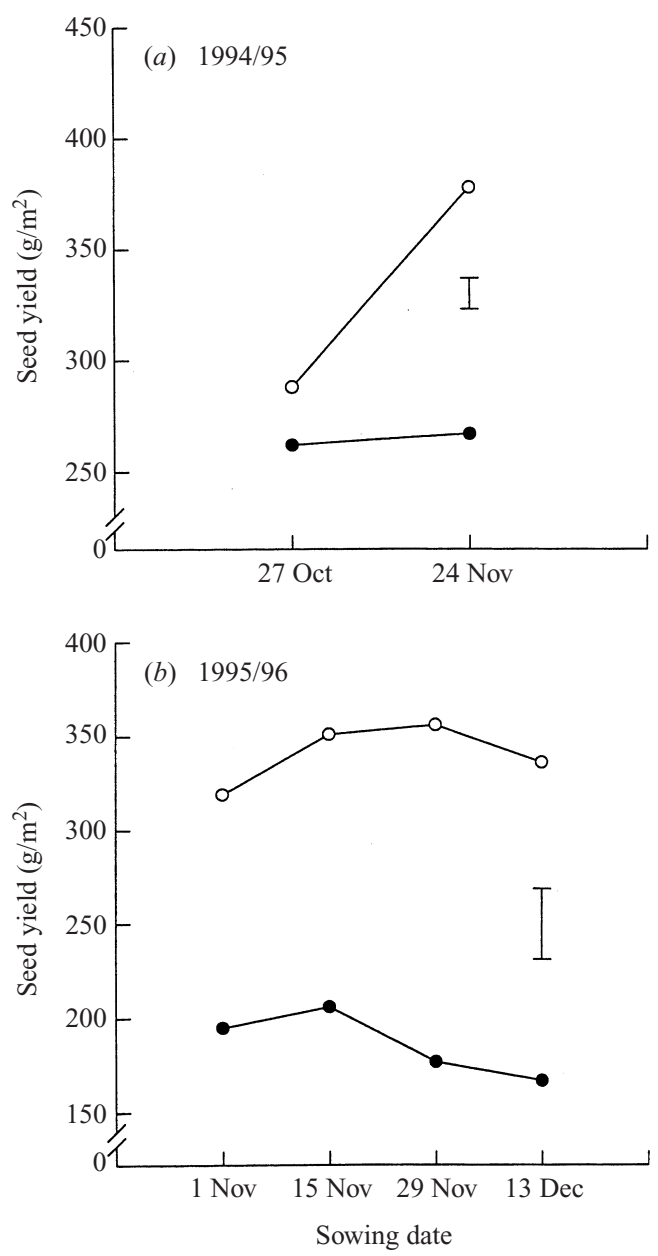

Fig. 2. The irrigation $\times$ sowing date interaction on pinto beans seed yield in (a) 1994/95 and (b) 1995/96; (unirrigated (O), irrigated $(O)$; $\mathrm{I}=$ S.E.M, error D.F. for $(a)=30$ and $(b)=18)$.

$\mathrm{mm}$ ) being $c .60 \%$ of the long-term average. However, rainfall in March 1996 was 13\% higher than normal. While mean maximum temperatures were similar to normal, mean minimum temperatures during the season were c. $14 \%$ above average. Penman EPT was also $c .18 \%$ higher than normal.

\section{Total dry matter (TDM)}

In 1994/95, the effect of irrigation on TDM depended on sowing date. When sown in October, irrigation increased TDM by $15 \%$ from 453 to $523 \mathrm{~g} / \mathrm{m}^{2}$ (Fig. $1 a$ ). For the November sowing, irrigated crops produced $579 \mathrm{~g}$ TDM $/ \mathrm{m}^{2}, 37 \%$ more TDM than unirrigated crops (Fig. 1a). Irrigated November crops also had $11 \%$ greater TDM than irrigated October crops. 


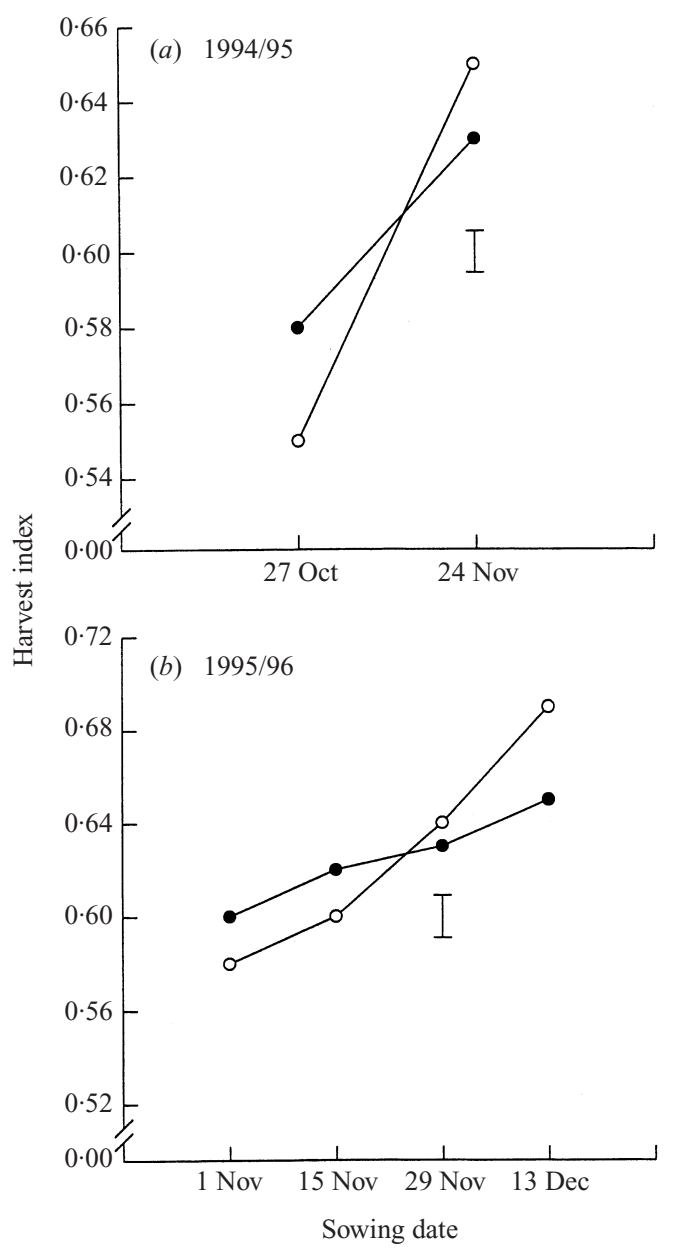

Fig. 3. The irrigation $\times$ sowing date interaction on harvest index of pinto beans in (a) 1994/95 and (b) 1995/96; (unirrigated $(\bullet)$, irrigated $(\bigcirc)$; I = S.E.M, error D.F. for $(a)=30$ and $(b)=18)$.

In $1995 / 96$, there was no irrigation by sowing date interaction. However, full irrigation increased TDM production by $74 \%$ (Fig. $1 \mathrm{~b}$ ). Averaged over both years irrigated crops produced $50 \%$ more TDM than unirrigated crops. Total dry-matter production ranged from $371 \mathrm{~g} / \mathrm{m}^{2}$ in the December sowing to $461 \mathrm{~g} / \mathrm{m}^{2}$ in the mid-November sowing (Fig. 1c). Total dry matter at harvest over the two seasons among sowing dates ranged from 371 to $501 \mathrm{~g} / \mathrm{m}^{2}$, with crops grown in 1994/95 on average producing $c$. $15 \%$ more TDM than the $1995 / 96$ crops.

\section{Seed yield and harvest index (HI)}

In both years, there was a significant irrigation $x$ sowing date interaction on seed yield $(P<0.05)$; i.e., the response to irrigation depended on sowing date.

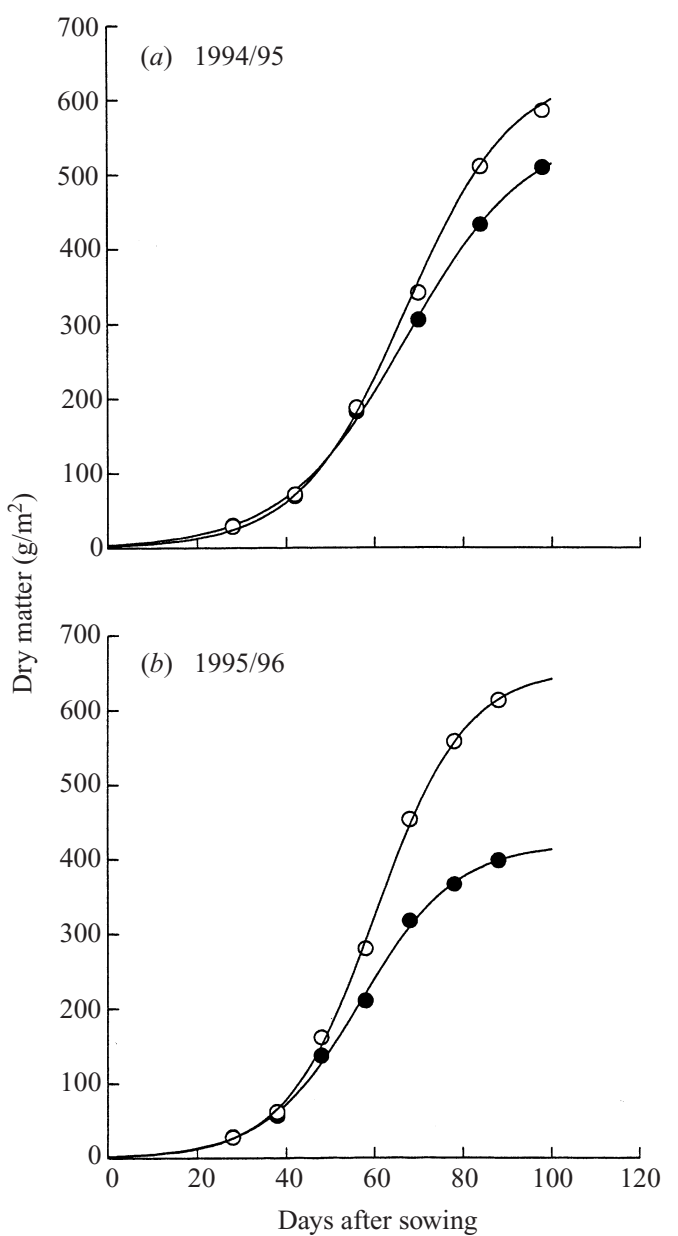

Fig. 4. Influence of irrigation on dry matter accumulation of pinto beans, averaged over all sowing dates, in Canterbury in (a) 1994/95 and (b) 1995/96; (unirrigated ( ), irrigated $(\bigcirc)$ ).

In $1994 / 95$, irrigation increased seed yield by only $10 \%$ in the October sowing, but it resulted in a $42 \%$ increase in the November sowing (Fig. 2a). In addition, irrigated November-sown crops yielded $31 \%$ more than irrigated October-sown crops, but there was no difference in yield between the unirrigated crops. Similarly in 1995/96, the increase in seed yield due to irrigation ranged from $64 \%$ in the early November sowing to $100 \%$ in the late November and December sown crops (Fig. $2 b$ ). Seed yield ranged from 262 to $378 \mathrm{~g} / \mathrm{m}^{2}$ and from 167 to $356 \mathrm{~g} / \mathrm{m}^{2}$ in $1994 / 95$ and 1995/96, respectively. On average, the $1994 / 95$ season crops yielded $c .15 \%$ more seed than the $1995 / 96$ crops.

As with TDM and seed yield, the significant interaction of irrigation $\times$ sowing date $(P<0.05)$ also showed that the response of HI to irrigation depended 


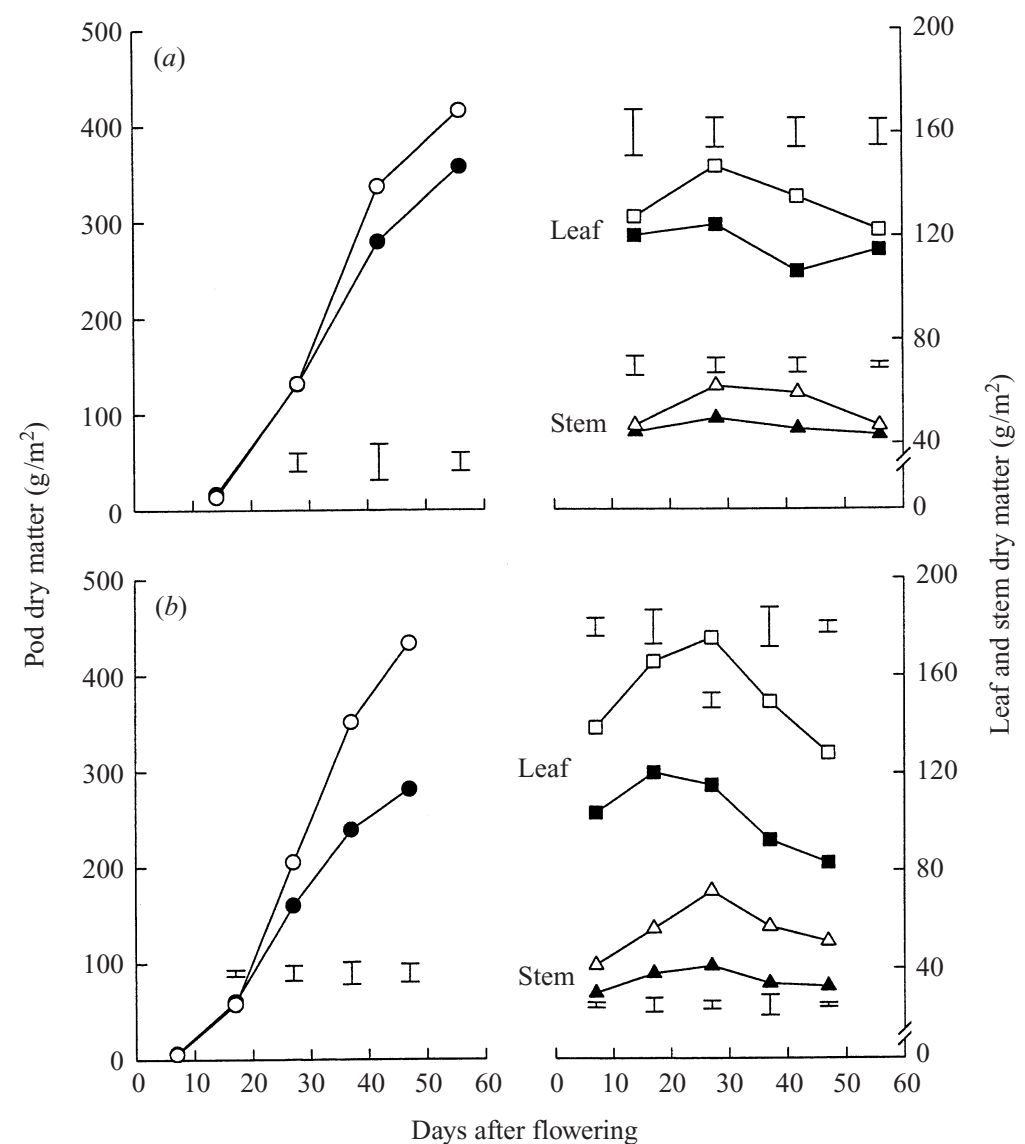

Fig. 5. The change in pod $(\bigcirc, \mathbf{O})$, leaf $(\boldsymbol{\square}, \square)$ and stem $(\boldsymbol{\Delta}, \triangle)$ dry matter over the growing season, averaged over all sowing dates, in unirrigated (closed) and irrigated (open) pinto beans in Canterbury in (a) 1994/95 and (b) 1995/96; (I = S.E.M; error D.F. for $(a)$ and $(b)=3)$.

on sowing date. With full irrigation, HI decreased slightly from 0.58 to 0.55 for the October-sown plants, while it increased slightly from 0.63 to 0.65 for the November-sown plants in 1994/95 (Fig. 3 a). Similarly in 1995/96, full irrigation caused a slight reduction in $\mathrm{HI}$ in the early and mid-November sown crops, but $\mathrm{HI}$ in the December crop was increased by $21 \%$ (Fig. $3 b)$.

\section{Dry matter accumulation}

In both years, the fully irrigated crops averaged over all sowing dates, initially accumulated DM slowly, similar to the unirrigated crops up to c. 40 DAS; thereafter DM accumulation was more rapid in irrigated crops (Fig. 4). The weighted mean absolute growth rate (WMAGR) and maximum crop growth rate $\left(C_{m}\right)$ for fully irrigated crops were almost double (12.6 and $19.5 \mathrm{~g} / \mathrm{m}^{2}$ per day, respectively) that of the unirrigated crops $\left(6.6\right.$ and $9.8 \mathrm{~g} / \mathrm{m}^{2}$ per day, respectively). Similarly the November-sown crops had $49 \%$ higher WMAGR (10.6 v. $7 \cdot 1 \mathrm{~g} / \mathrm{m}^{2}$ per day) and
$61 \%$ higher $C_{m}\left(16 \cdot 5 v \cdot 10 \cdot 2 \mathrm{~g} / \mathrm{m}^{2}\right.$ per day $)$ than the December-sown crops (data not shown).

\section{Pod, stem and leaf growth}

Pod growth in the irrigated plants (averaged over all sowing dates) was similar to the pod growth in the unirrigated plants during the initial phase (c. 2-3 weeks after flowering) in both years. Thereafter, pods on the irrigated plants grew faster and were heavier than the unirrigated plants (Fig. $5 a, \mathrm{~b}$ ). Averaged over both years, the WMAGR and $C_{m}$ were 10.9 and $16 \cdot 1 \mathrm{~g} / \mathrm{m}^{2}$ per day, respectively, for irrigated crops, compared with 7.5 and $11 \mathrm{~g} / \mathrm{m}^{2}$ per day, respectively, for unirrigated crops. Stems and leaves of both unirrigated and irrigated crops averaged over all sowing dates, increased in dry weight for $c .24$ days after flowering, and then began to lose weight up until crop maturity (Fig. 5a,b). At maturity, the stem and leaf DM had decreased to an average (over both seasons) of c. 85 and $73 \%$ of their maximum values in 


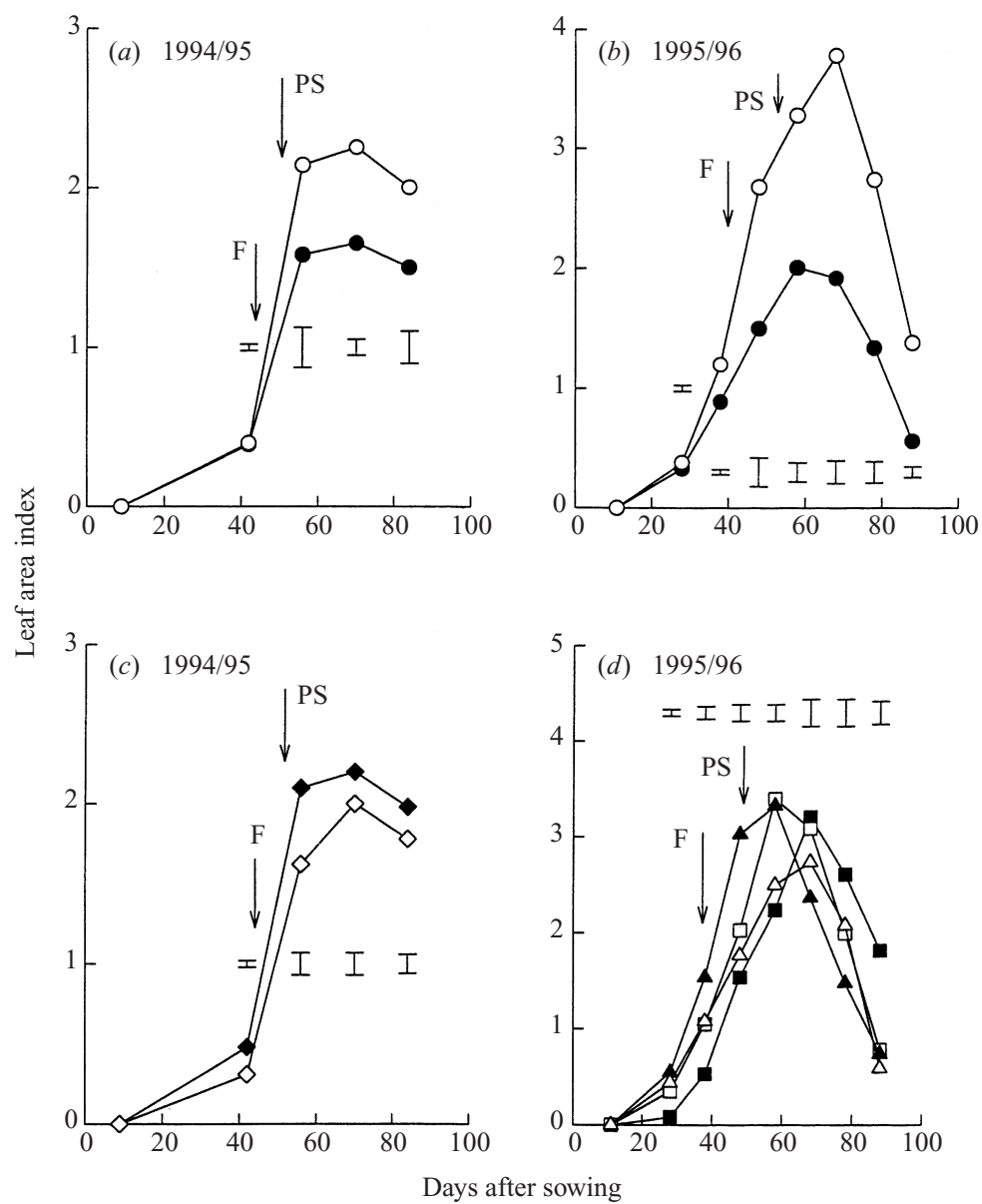

Fig. 6. Leaf area index over the growing season of pinto beans in 1994/95 and 1995/96. (a) and (b) (unirrigated (O), irrigated $(\bigcirc)$; $(c)$ Oct. $27(\diamond)$, Nov. $24(\diamond)$; $(d)$ Nov. $1(\boldsymbol{\square})$, Nov. $15(\square)$, Nov. $29(\boldsymbol{\Delta})$, Dec. $13(\triangle)$. (F =flowering, PS=pod set; $\mathrm{I}=$ S.E.M, error D.F. for $(a)$ and $(b)=3,(c)=30$ and $(d)=18$.)

the unirrigated and irrigated crops, respectively (Fig. $5 a, b)$. The contribution of assimilates stored in the leaf and stem to pod growth was calculated as the ratio of the difference between maximum leaf and stem DM and leaf and stem DM at maturity: pod DM at maturity (Husain et al. 1988). Irrigated crops contributed c. $15 \%$ to pod growth compared with $c$. $10 \%$ by unirrigated crops. Similarly the mid- to late November sowings contributed c. $26 \%$ compared with $13 \%$ in the October and early November-sown plants; and $5 \%$ in the December plants.

\section{Leaf area index (LAI)}

In both seasons, the differences in leaf area index (LAI) between the irrigation treatments became significant after 40 DAS with higher LAIs in the fully irrigated crops than the unirrigated crops (Fig. $6 a, b$ ). Maximum LAI ranged from 1.65 to $2 \cdot 0$ in unirrigated crops and from 2.55 to 3.78 in irrigated crops in both seasons.

In 1994/95, LAI varied between sowing dates, with the October sowing producing higher LAI after 40 DAS (Fig. 6c). In 1995/96, LAI developed more slowly in the early November-sown plants. The increase in LAI was most rapid in the mid- and late November-sown plants which reached a maximum LAI of $c .3 .5$ at 60 DAS (Fig. $6 d$ ). The early November and December-sown crops reached maximum LAIs of $3 \cdot 2$ and $2 \cdot 7$, respectively. The decline in LAI was fastest in the late November sown crops (Fig. 6d).

Leaf area duration (LAD)

The fully irrigated crops had $37 \%$ and $57 \%$ longer LAD than the unirrigated crops in 1994/95 and 1995/96 respectively (data not shown). In 1994/95, the October sowing produced $18 \%$ higher LAD than 

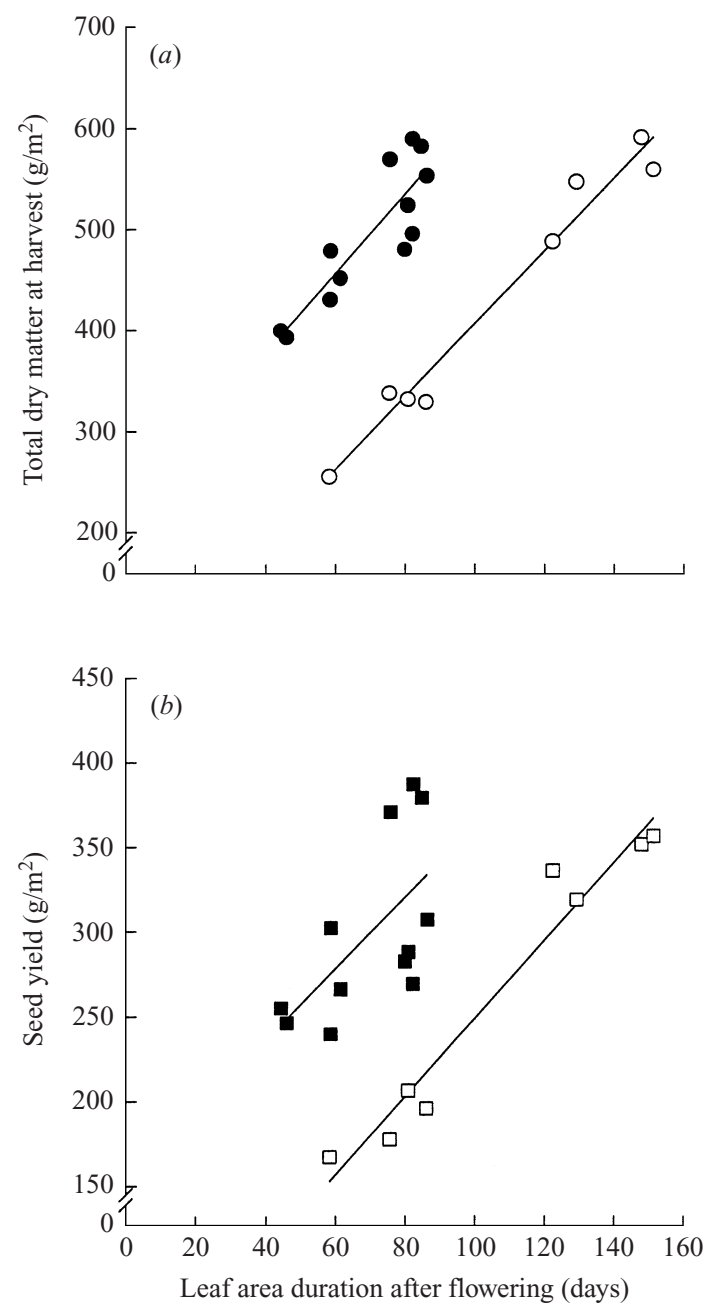

Fig. 7. The relationship between leaf area duration after flowering and $(a)$ total dry matter $(1994 / 95(0) \mathrm{Y}=221+$ $3.89 \mathrm{X}, r=0.87$; 1995/96 (○) $\mathrm{Y}=45+3 \cdot 60 \mathrm{X}, r=0.98 ;(b)$ seed yield $(1994 / 95(\square) \mathrm{Y}=152+2 \cdot 09 \mathrm{X}, r=0 \cdot 62 ; 1995 / 96$ ( $\square) \mathrm{Y}=18+2 \cdot 30 \mathrm{X}, r=0.97)$.

the November sowing. However, in 1995/96, the early November sowing had a LAD of 142 days, c. $33 \%$ less than the LAD of the mid- and late November sowings and $27 \%$ less than the December sowing.

Total dry matter (TDM) production in both seasons was linearly and significantly correlated with LAD from emergence to maturity $\left(r^{2}=0.70\right.$ in 1994/95 and $r^{2}=0.60$ in 1995/96). The TDM and LAD after flowering were strongly related in both seasons $\left(r^{2}=0.76\right.$ in $1994 / 95$ and $r^{2}=0.96$ in 1995/96) (Fig. 7 a). Similarly, seed yield was linearly related with LAD in both seasons. However, while seed yield was poorly correlated with LAD from E-M $\left(r^{2}=0 \cdot 30\right)$ or LAD after flowering $\left(r^{2}=0 \cdot 38\right)$ in $1994 / 95$, it was strongly related to LAD from E-M $\left(r^{2}=0 \cdot 60\right)$ and LAD after flowering $\left(r^{2}=0 \cdot 95\right)$ in $1995 / 96$ (Fig. $7 b$ ).

\section{Radiation interception, intercepted PAR, DM accumulation and crop yield}

All irrigated crops intercepted up to $84-95 \%$ of incident radiation (Fig. $8 a, b$ ). However, unirrigated crops intercepted $c .72-78 \%$ of incident radiation. In $1995 / 96$, all sowing dates intercepted $c .80-93 \%$ of incident radiation (Fig. $8 d$ ). There was a highly significant linear relationship between accumulated DM production and cumulative intercepted PAR in both seasons. Irrigated crops (averaged over all sowing dates) accumulated both DM and PAR faster than the unirrigated crops in both seasons with an average $u$ of $1.23 \mathrm{~g} \mathrm{DM} / \mathrm{MJ}$ PAR, $22 \%$ higher than the unirrigated crops (1.01) (Fig. 9a). In 1994/95, the November-sown crops accumulated DM and PAR faster than the October-sown crops and had $u$ values of 1.22 and $1.02 \mathrm{~g} \mathrm{DM} / \mathrm{MJ}$ PAR, respectively (Fig. $9 b$ ). There were no differences in $u$ among sowing dates in 1995/96.

\section{DISCUSSION}

Influence of irrigation on growth and development of pinto beans

Seed yield in both seasons was highly correlated with TDM, hence high DM production may be a prerequisite for high pinto bean yields as was found in chickpea by Saxena et al. (1990). Averaged over both growing seasons, irrigation increased both TDM production and seed yield by $c .50 \%$; and resulted from increased leaf area index (LAI), leaf area duration (LAD), intercepted solar radiation and high crop growth rates. The faster pod growth and heavier pods also accounted for the higher seed yield in irrigated crops compared with unirrigated crops. The increase in TDM production and seed yield with irrigation is consistent with work on $P$. vulgaris (Bonanno \& Mack 1983; Acosta Gallegos \& Shibata 1989).

It has also been found that irrigation can more than double the yield of grain legumes in Canterbury (White et al. 1982; Husain et al. 1983). Overall TDM production and seed yield in 1995/96 were c. $15 \%$ lower than in 1994/95, which might have been the result of the dry conditions in November-January when total rainfall was only $65 \%$ of that in the previous year. These results suggest that in a dry Canterbury spring-summer season as experienced in the 1994/95 and 1995/96 seasons, irrigating pinto beans throughout the season would be necessary to produce high seed yield.

The rapid increase in DM accumulation caused by irrigation, as shown in Fig. 4 is consistent with work on navy beans (Bonanno \& Mack 1983), Vicia faba 

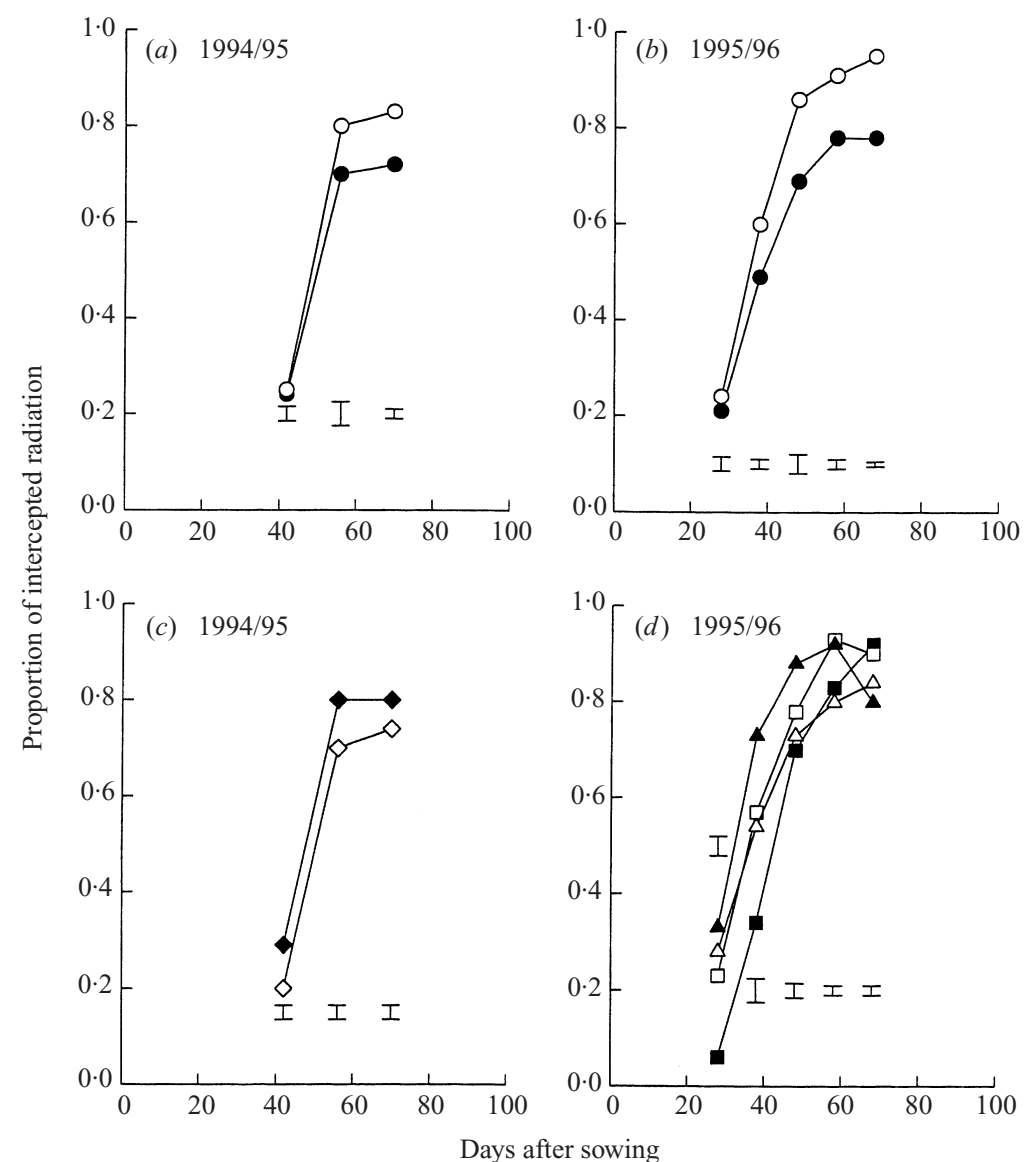

Fig. 8. The proportion of intercepted radiation up to maximum leaf area index by pinto beans in 1994/95 and 1995/96. $(a)$ and $(b)$ unirrigated $(\bullet)$, irrigated $(\bigcirc) ;(c)$ Oct. $27(\diamond)$, Nov. $24(\diamond) ;(d)$ Nov. $1(\boldsymbol{\square})$, Nov. $15(\square)$, Nov. $29(\boldsymbol{\Delta})$, Dec. $13(\triangle)$. $(\mathrm{I}=$ S.E.M, error D.F. for $(a)$ and $(b)=3,(c)=30$ and $(d)=18$.)

(Husain et al. 1988) and chickpeas (Khanna-Chopra \& Sinha 1987). Irrigation caused faster leaf area development resulting in canopy closure, and had longer LAD which resulted in more intercepted radiation.

The sigmoid pod growth curves were similar to those for grain growth in wheat (Gallagher \& Biscoe 1978) and soyabeans (Egli 1975). Pods from the unirrigated crops grew at a slower rate compared with the irrigated crops because of a shortfall in assimilate supply due to lower LAI, LAD, hastened leaf senescence resulting in low intercepted radiation (Singh 1991; White \& Izquierdo 1991). Husain et al. (1988), however, found that pods from unirrigated and irrigated Vicia faba plants grew at a similar rate, because the unirrigated plants produced fewer pods per plant and were able to use stem DM to sustain pod growth. Remobilization of stored assimilates from leaves and stems appeared important for podfilling in irrigated plants (i.e. they remobilized a greater percentage to sustain the growth rates of their pods). The percentage of stored assimilates contributed to pod growth over the two seasons reported here are comparable to the $15-20 \%$ reported for chickpeas (Singh 1991) and 20\% for irrigated Vicia faba in Canterbury (Husain et al. 1988). However, it is lower than the $46 \%$ obtained for unirrigated Vicia faba (Husain et al. 1988).

Irrigation caused large increases in maximum LAI in both years; $54 \%$ in 1994/95 and $89 \%$ in 1995/96. In Canterbury, similar increases in the LAI due to irrigation in grain legumes have also been reported (Zain 1984; Husain et al. 1988; McKenzie 1987). Water stress caused substantial reductions in LAI in beans (Bonanno \& Mack 1983; Acosta Gallegos \& Shibata 1989). Variation in LAI in response to irrigation may sometimes be accounted for by differences in leaf appearance rate (Farah 1981), overall leaf number and expansion and senescence of green area (Sinclair 1994). 


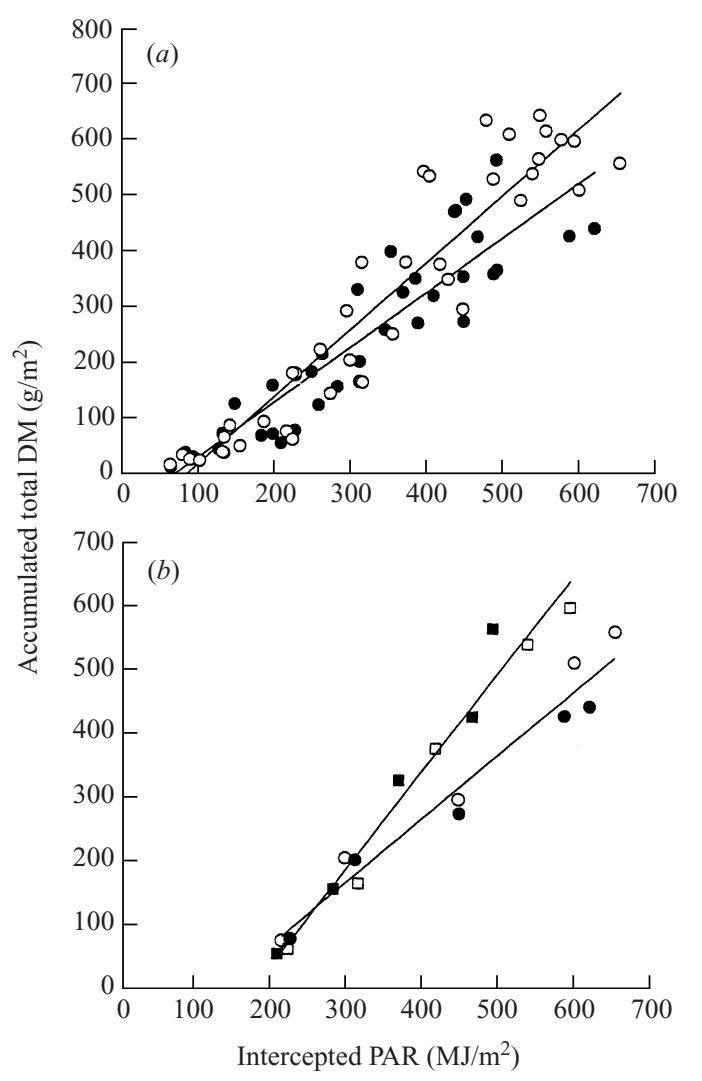

Fig. 9. The relationship between accumulated dry matter and intercepted PAR for $(a)$ unirrigated $(\bullet)(\mathrm{Y}=-70+$ $1 \cdot 01 \mathrm{X}, r=0.91)$ and irrigated $(\mathrm{O})(\mathrm{Y}=-104+1 \cdot 23 \mathrm{X}$, $r=0.94)$ pinto beans averaged over all sowing dates in both seasons; and $(b)$ Oct. $27(\boldsymbol{\square})(\mathrm{Y}=-136+1 \cdot 02 \mathrm{X}, r=0 \cdot 98)$ and Nov. $24(\square) \mathrm{Y}=-279+1.57 \mathrm{X}, r=0.98)$ sown pinto beans in 1994/95.

The greater LAI in the irrigated crops also translated into greater LAD. Irrigation increased LAD in both seasons through increased maximum LAI and delayed leaf senescence (McKenzie 1987; Husain et al. 1988). The high correlation of LAD from emergence to maturity or most especially LAD after flowering with TDM and seed yield was also reported for lentils (McKenzie 1987) and peas (Zain 1984) in Canterbury. Laing et al. (1984) also reported that LAD explained a large proportion of the variation in seed yield $\left(r^{2}=0.99\right)$ of eight grain legume species.

The marked difference in the proportion of intercepted radiation $\left(F_{i}\right)$ between the unirrigated and irrigated crops after 40 DAS (Fig. $9 a, b$ ) was due to the decline in LAI or incomplete canopy closure in the unirrigated crops. Radiation interception and LAI are closely linked (Gardner \& Auma 1989) and in India, Singh (1991) found in chickpeas that a decrease in LAI caused a corresponding reduction in radiation interception by the canopy and TDM production. The higher accumulation or production of dry matter from the fully irrigated plants compared with unirrigated plants was associated with a greater interception of PAR and a $22 \%$ higher $u$.

\section{Influence of sowing date on growth and development of pinto beans}

The $31 \%$ increase in seed yield in the irrigated November-sown crops over the irrigated Octobersown crops in 1994/95, and the $100 \%$ increase in the irrigated mid- and late November-sown plants compared with the $64 \%$ increase in early November plants in 1995/96, were due to the higher LAI, LAD, crop growth rates and more rapid pod growth. An increase in intercepted PAR $(21 \%$ v. 5-8\%) and HI also contributed to the higher yield in the irrigated mid- to late November sowings.

The HI values obtained in this study were high and ranged from 0.53 to 0.69 . This could have been due to leaf shedding near maturity, a phenomenon common in grain legumes (Khanna-Chopra \& Sinha 1987). The irrigated October and early November-sown crops tended to have lower HI because of increased TDM production without a corresponding increase in seed yield.

The differences in seasonal DM among sowing dates, especially in 1995/96 resulted mainly from differences in the derived growth variates (WMAGR and $C_{m}$ ). The $C_{m}$ values achieved in this study were within the range $14-18 \mathrm{~g} / \mathrm{m}^{2}$ per day reported for $P$. vulgaris by various studies in White \& Izquierdo's (1991) review. However, they were lower than those of other grain legumes in Canterbury: $25 \mathrm{~g} / \mathrm{m}^{2}$ per day for irrigated peas (Zain 1984) and $22 \mathrm{~g} / \mathrm{m}^{2}$ per day for autumn sown field beans (Husain et al. 1988).

On average, pods from the mid- to late Novembersown crops were c. $22 \%$ heavier and grew $55 \%$ faster than the October-sown crops in 1994/95 and 10\% heavier and $58 \%$ faster than the December crops in 1995/96 due to higher LAD, intercepted PAR and utilization coefficient. They also had greater stored assimilates in the stem and leaf contributing to pod growth than the October and November-sown crops.

It is likely that the higher plant population of the October-sown crops (56 plants $/ \mathrm{m}^{2}$ ) compared with the November-sown crops ( 50 plants $\left./ \mathrm{m}^{2}\right)$ caused the slightly higher LAI in the October sown plants in $1994 / 95$. The rapid reduction in the LAI of the midand late November sowings after 60 DAS may primarily have been due to increased leaf senescence.

The greater LAI in the mid- to late Novembersown crops also translated into greater LAD. The reduction in LAI in the early November-sown plants, and the reduction in maximum LAI combined with the rapid senescence in the December-sown plants, 
may have resulted in the reduction in LAD in 1995/96. The results also indicated that the rapid rate of senescence in the mid- and late November sowings did not offset the effects of the larger LAI on LAD. Similarly, the mid- and late November sowings intercepted more radiation because of increased LAI over the early November and December sowings. The November-sown crops accumulated DM and PAR faster and had a $u$ value of $1.23 \mathrm{~g} \mathrm{DM} / \mathrm{MJ}$ PAR, $20 \%$ higher than the October-sown crops in 1994/95.

\section{The interaction of irrigation and sowing date}

Both TDM production at final harvest and seed yield were affected by irrigation and sowing date. However, sowing date appeared to be the major factor as the irrigation $\times$ sowing date interactions indicated the response to irrigation depended on the sowing date. It appears from the results that in a dry season, or in the absence of irrigation, highest yield would be obtained by sowing as early as possible (i.e. late October/early November), where the crops could avoid drought thereby completing pod filling early in the season before moisture stress becomes limiting. It also indicated that irrigation did not only increase yield, but also allowed sowing date to be delayed without incurring any yield loss.

The effect of irrigation on total intercepted PAR was most significant with delayed sowing in both seasons. Intercepted PAR increased 5 and $21 \%$ in
October and November-sown crops, respectively in 1994/95; and 8, 21 and $38 \%$ increase in early November, the mid- to late November and Decembersown crops, respectively in 1995/96. The differences in incident solar radiation due to sowing date, combined with variation in canopy characteristics (LAI, $k$ (data not presented) and LAD) accounted for the differences in total intercepted PAR among sowing dates and between irrigation treatments within sowing dates.

This work has shown that pinto beans can be a very productive crop (yielding $c .378 \mathrm{~g} / \mathrm{m}^{2}$ ) in Canterbury, New Zealand. Seed yield in response to irrigation and sowing date was accounted for by differences in the amount of DM produced and intercepted PAR. Therefore crop management should aim to maximize the duration of crop growth and hence the opportunity to intercept more PAR. Thus for optimization of yield of pinto beans, it should be sown in mid- to late November with adequate plant population and irrigated to achieve increased crop growth rates before or during pod growth through increased LAI, LAD and intercepted PAR.

The authors thank the New Zealand Ministry of Foreign Affairs and Trade and Lincoln University for scholarships for H. K. Dapaah; the Lincoln University Research Committee for funds; and D. W. Jack and D. J. Heffer for technical assistance.

\section{REFERENCES}

Acosta Gallegos, J. A. \& Shibata, J. K. (1989). Effect of water stress on growth and yield of indeterminate drybean (Phaseolus vulgaris) cultivars. Field Crops Research 20, 81-93.

ANon. (1968). New Zealand Soil Bureau. General survey of soils of the South Island, New Zealand. Soil Bureau Bulletin 27.

AnON. (1988). Statistical Analysis System Institute. SAS/ STAT Users Guide Release. Cary, NC: SAS Institute Inc.

Bonanno, A. R. \& MACK, H. J. (1983). Water relations and growth of snap beans as influenced by differential irrigation. Journal of the American Society of Horticultural Science 108, 837-844.

EGLI, D. B. (1975). The rate of accumulation of dry weight in seed of soybeans and its relationship to yield. Canadian Journal of Plant Science 55, 215-219.

FARAH, S. M. (1981). An examination of the effects of water stress on leaf growth of crops of field beans (Vicia faba L.). I. Crop growth and yield. Journal of Agricultural Science, Cambridge 96, 327-336.

Gallagher, J. N. \& Biscoe, P. V. (1978). A physiological analysis of cereal yield. II. Partitioning of dry matter. Agricultural Progress 53, 51-70.

Gallagher, J. N. \& Robson, A. B. (1984). Fitting growth sigmoidal curves using MLP - an interim guide. New Zealand, Lincoln College, 9 pp.

Gardner, F. P. \& Auma, E. O. (1989). Canopy structure, light interception, and yield and market quality of peanut genotypes as influenced by planting pattern and planting date. Field Crops Research 20, 13-29.

HunT, R. (1978). Plant growth analysis. Institute of Biological Studies in Biology 96, 26-38.

Husain, M. M., Gallagher, J. N., Hill, G. D., Othman, M. \& ReID, J. B. (1983). The non-existence of moisture sensitive phases in Vicia faba L. in Canterbury. Proceedings of the Agronomy Society of New Zealand 13, 87-94.

Husain, M. M., Hill, G. D. \& Gallagher, J. N. (1988). The response of field beans (Vicia faba L.) to irrigation and sowing date. 2. Growth and development in relation to yield. Journal of Agricultural Science, Cambridge 111, 233-254.

Khanna-Chopra, R. \& Sinha, S. K. (1987). Chickpea: physiological aspects of growth and yield. In The Chickpea (Eds M. C. Saxena \& K. B. Singh), pp. 163-189. Wallingford: CAB International.

Laing, D. R., Jones, P. G. \& Davis, J. H. C. (1984). Common beans (Phaseolus vulgaris L.). In The Physiology of Tropical Field Crops (Eds P. R. Goldsworthy \& N. M. Fisher), pp. 305-351. New York: John Wiley.

McKenZIE, B. A. (1987). The growth, development and water use of lentils (Lens culinaris Medik.). $\mathrm{PhD}$ thesis, Lincoln College, University of Canterbury, New Zealand.

McKenzie, B. A. \& Hill, G. D. (1990). Growth, yield and water use of lentils (Lens culinaris) in Canterbury, New Zealand. Journal of Agricultural Science, Cambridge 114, 309-320. 
McKenzie, B. A., Sherrell, C., Gallagher, J. N. \& Hill, G. D. (1985). Response of lentils to irrigation and sowing date. Proceedings of the Agronomy Society of New Zealand 15, 47-50.

Ross, G. J. S., Hawkins, D., Jones, R. D., Kempton, R. A., Laucker, F. B., Payne, R. W. \& White, R. P. (1987). MLP - Maximum Likelihood Programme. Harpenden: Rothamsted Experiment Station.

SaXena, M. C., Silim, S. N. \& Singh, K. B. (1990). Effect of supplementary irrigation during reproductive growth on winter and spring chickpea (Cicer arietinum L.) in a Mediterranean environment. Journal of Agricultural Science, Cambridge 114, 285-293.

Sinclair, T. R. (1994). Limits to crop yield. In Physiology and Determination of Crop Yield (Eds K. J. Boote, J. M. Bennett, T. R. Sinclair \& G. M. Paulsen), pp. 200-220. Madison, WI: ASA, CSSA, SSSA.
SinGH, P. (1991). Influence of water-deficits on phenology, growth and dry matter allocation in chickpea (Cicer arietinum). Field Crops Research 28, 1-15.

SzeIcz, G. (1974). Solar radiation in crop canopies. Journal of Applied Ecology 11, 1117-1156.

White, J. W. \& Izquierdo, J. (1991). Physiology of yield potential and stress. In Common Beans: Research for Crop Improvement (Eds A. van Schoonven \& O. Voysest), pp. 287-382. Wallingford: CAB International.

White, J. G. H., Sheath, G. W. \& Meijer, G. (1982). Yield of garden pea - field response to variation in sowing rates and irrigation. New Zealand Journal of Experimental Agriculture 10, 155-160.

ZAIN, Z. M. (1984). The effect of irrigation on radiation absorption, water use efficiency and yield of commercial and semi-leafless peas. MAgrSc thesis, Lincoln College, University of Canterbury, New Zealand. 